\title{
RANCANG BANGUN ALAT PENGERING RUMPUT LAUT BERBASIS MIKROKONTROLER ARDUINO UNO
}

\author{
Oleh \\ Anak Agung Gde Ekayana \\ Jurusan Pendidikan Teknik Elektro, FTK, UNDIKSHA \\ gungekayana@yahoo.com
}

\begin{abstract}
ABSTRAK
Rumput laut merupakan bahan baku dari berbagai jenis produk olahan yang bernilai ekonomi tinggi. Rumput laut banyak dijual dalam keadaan kering. Proses pengeringan rumput laut dilakukan secara alami dengan menggunakan sinar matahari yang membutuhkan waktu pengeringan selama 3 sampai dengan 4 hari, ini yang menjadi masalah bagi petani rumput laut. Penelitian ini bertujuan membuat suatu rancangan alat yang dapat mengeringkan rumput laut, yang dapat digunakan oleh petani rumput laut dapat mengeringkan rumput laut. Rancang bangun alat pengering rumput laut menggunakan elemen pemanas sebagai pengganti sinar matahari untuk proses mengeringkan rumput laut. Sensor DHT11 digunakan untuk mengukur suhu dan kelembaban, yang kemudian ditampilkan pada LCD. Mikrokontroler Arduino Uno digunakan sebagai kendali alat pengeringan rumput laut. Hasil pengujian keseluruhan menunjukkan bahwa alat pengering rumput laut ini mampu mengeringkan rumput laut selama \pm 7 jam. Sensor DHT11 mampu merespon perubahan nilai suhu dan kelembaban dari proses pengeringan . pada tampilan LCD dapat diperhatikan monitoring suhu dan kelembaban, jika suhu udara meningkat, maka kelembaban udara akan menurun. Hasil pengujian memberikan data bahwa rumput laut kering dengan tingkat kelembaban $>60 \%$.
\end{abstract}

Kata-kata kunci : Mikrokontroler, Element pemanas, DHT11, Arduino

\begin{abstract}
Seaweed is the raw material of various kinds of processed products of high economic value. Seaweed is sold in a dry state. Seaweed drying process is done naturally using sunlight requires drying time for 3 to 4 days, this is a problem for seaweed farmers. This study aims to make a design tool that can dry seaweed, which can be used by seaweed farmers can dry grass laut. Design of wake seaweed dryers use heating element instead of sunlight for the process of drying the seaweed. DHT11 sensors used to measure temperature and humidity, which is then displayed on the LCD. Arduino Uno microcontroller is used as a control tool seaweed drying . Overall test results show that the dryer is capable of automatic seaweed drying seaweed for \pm 7 hours. DHT11 sensor capable of responding to changes in the value of the temperature and humidity of the drying process. the LCD display can be considered monitoring the temperature and humidity, if the air temperature increases, the air humidity will decrease. The test results provide data that dried seaweed with a humidity level of $>60 \%$.
\end{abstract}

Rancang Bangun Alat Pengering Rumput Laut...... (Anak Agung Gde Ekayana) 
Keywords: Microcontroller, Heater, DHT 11, Arduino

\section{PENDAHULUAN}

Bali merupakan salah satu provinsi di Indonesia yang terkenal dengan pertanian dan budayanya yang khas, sector tersebut merupakan salah satu aspek yang mampu menarik para wisatawan untuk berkunjung ke Bali, sehingga bali menjadi tujuan obyek pariwisata dan bali merupakan salah satu provinsi yang menopang pendapatan negara melalui devisa. Selain sebagai obyek pariwisata, Bali juga memiliki areal persawahan yang menjadi salah satu faktor daya tarik pariwisata.

Sawah merupakan salah satu sumber pendapatan sebagian dari masyarakat Bali, selain pertanian yang ada di darat, Bali juga mengembangkan budidaya di daerah laut. Tahun 1985 di Nusa Penida rumput laut mulai dikembangkan di sepanjang pesisir pantai dari sisi barat desa Toyapakeh sampai di sisi timur desa Suana. Hasil pengembangan rumput laut ini mampu mendongkrak penghasilan masyarakat terutama yang tinggal di daerah pesisir.

Rumput laut merupakan salah satu komoditas kelautan yang memiliki nilai ekonomi dan manfaat yang tinggi bagi manusia, karena rumput laut dapat diolah menjadi bahan dasar makanan dan berbagai jenis produk seperti: dodol rumput laut, agar-agar, obat-obatan, kosmetik, dan lain sebagainnya. Pengolahan rumput laut menjadi bahan dasar, tidak lepas dari proses panen dan pengeringan yang masih dianggap sebagai masalah oleh petani rumput laut sendiri.

Proses pengeringan rumput laut secara alami menggunakan bantuan sinar matahari yang membutuhkan waktu pengeringan 3 sampai dengan 4 hari sering menghambat kerja petani, sehingga petani rumput laut sering mengeluh karena cuaca yang tidak menentu terutama pada musim penghujan, petani sering gagal mengeringkan hasil panennya. Hujan yang turun secara terus menerus dapat menyebabkan rumput laut menjadi busuk dan tidak laku dijual, sehingga penghasilan masyarakat petani rumput laut menjadi tidak menentu. Permasalahan-permasalahan di atas perlu dicarikan solusi untuk mengatasinya, dengan cara merancang sebuah alat pengering yang tidak menggunakan sinar matahari, sehingga proses pengeringan rumput laut dapat dilakukan tanpa tergantung dengan sinar matahari. Alat yang dirancang secara teknologi memanfaatkan tenaga listrik dan mampu menghasilkan produksi rumput laut yang hasil keringnya sama dengan sinar matahari bahkan lebih baik dari yang pernah dilakukan oleh petani yang selama ini hanya menghandalkan sinar matahari atau secara alami. Berdasarkan latar belakang di atas, dipandang perlu dicarikan solusi untuk dapat mengeringkan rumput laut dengan efektif.

JPTK, UNDIKSHA, Vol. 13, No. 1, Januari $2016: 1$ - 12 


\section{METODE PENELITIAN}

Metode yang digunakan di dalam penelitian ini ada observasi dan wawancara tidak terstruktur kepada petani rumput laut, mengenai proses pengeringan rumput laut dengan cara manual (dijemur). Selanjutnya dari permasalahan tersebut dibuatkan rancang bangun alat pengering dengan menggunakan komponen elektronika untuk dapat mengeringkan rumput laut.

Alat pengering rumput laut ini adalah suatu alat yang dioprasikan oleh user dengan menekan tombol button, nantinya alat ini akan melakukan proses pengeringan rumput laut secara otomatis. Oleh karena itu diperlukan analisa sistem agar alat yang dibuat dapat memenuhi kebutuhan sistem, yaitu :

1. Alat mampu mengeringkan rumput laut.

2. Alat pengeringan rumput laut ini mampu menampung rumput laut sebanyak \pm 5 kilo gram.

3. Alat pengeringan rumput laut ini mampu menghilangkan kadar air dari rumput laut.

4. Alat pengeringan rumput laut ini mudah dipindahkan ketempat yang lebih aman sesuai keinginan user

Dari analisa sistem diatas dapat ditentukan kebutuhan sistem kebutuhan alat pengeringan rumput laut yang akan dibuat, yaitu :

1. Menggunakan LCD display 16x2 untuk menampilkan output sensor DHT11.

2. Menggunakan element pemanas heater AC $220 \mathrm{~V}$ sebagai dimmer pemanas.

3. Menggunakan driver relay 5 volt untuk menyalakan kipas.

4. Alat pengeringan rumput laut ini nantinya akan didesain menyerupai oven dengan menggunakan plat stainless sebagai tempat untuk pemrosesan rumput laut.

5. Menggunakan power supply yang berfungsi sebagai pensuplai daya keseluruh komponen elektronik

6. Menggunakan mikrokontroler Arduino Uno sebagai pusat pemrosesan data pada alat pengering rumput laut .

7. Menggunakan sensor DHT11 untuk mengukur kelembaban dan suhu.

8. Pada alat ini juga akan dipasang kipas yang digunakan untuk mendistribusikan panas.

9. Pada alat ini juga di pasang tombol (Push Buttton) yang digunakan sebagai tombol untuk menyalakan alat dan mematikan alat.

Rancang Bangun Alat Pengering Rumput Laut...... (Anak Agung Gde Ekayana) 


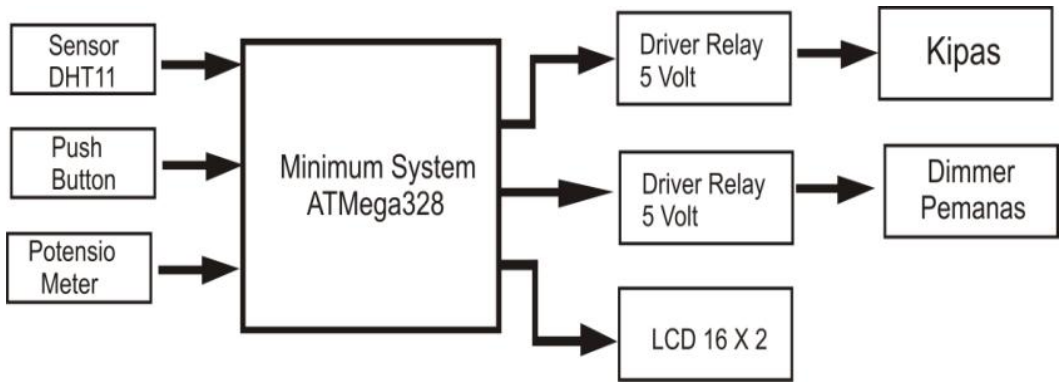

Gambar 1. Blok Diagram Alat Pengering Rumput Laut

Alat ini di desain dengan panjang $40 \mathrm{~cm}$ dan tinggi $40 \mathrm{~cm}$ sedangkan lebar samping $40 \mathrm{~cm}$, untuk panjang dalam box untuk penampungan rumput laut $38 \mathrm{~cm}$ sedangkan tinggi dalam box $36 \mathrm{~cm}$ dan panjang samping $35 \mathrm{~cm}$. Berikut dibawah ini desain dari alat pengering rumput laut yang terlihat dari tampak depan.

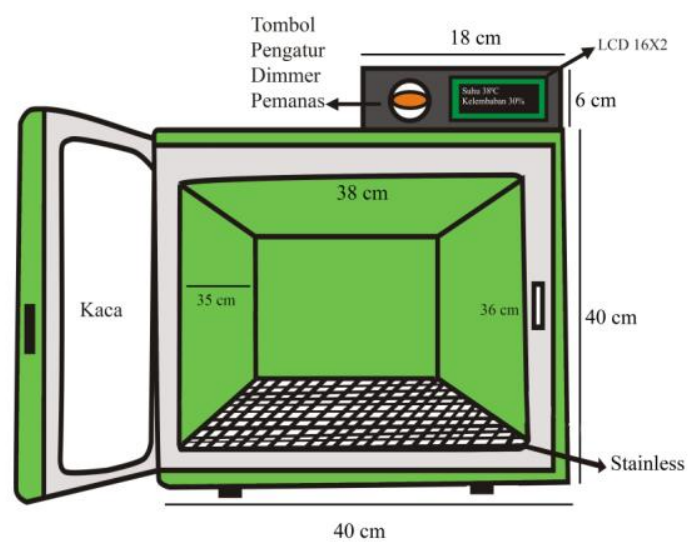

Gambar 2. Pandangan Depan Rancang Bangun Alat Pengering Rumput Laut

Berikut adalah penempatan komponen pada body box dari rancang bangun alat pengering rumput laut dilihat pada Gambar 3 dibawah ini.

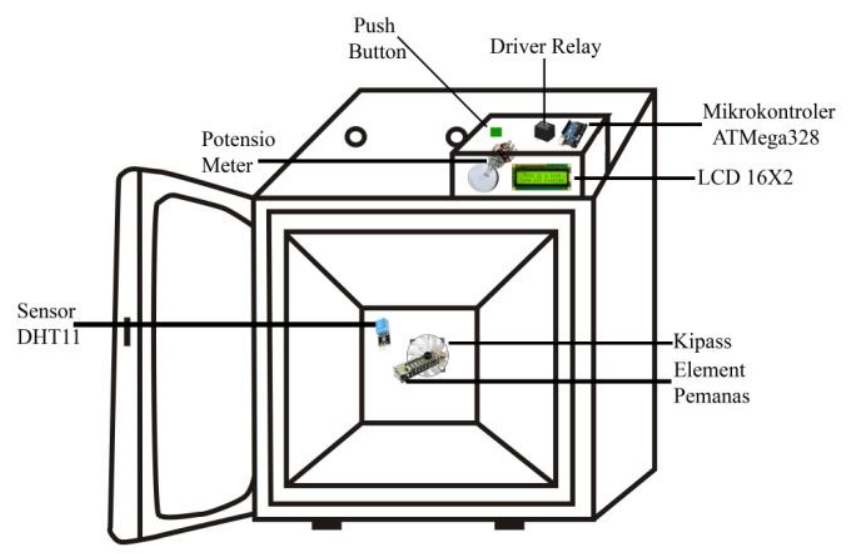

Gambar 3. Rancangan Penempatan Komponen Pada Alat Pengering

JPTK, UNDIKSHA, Vol. 13, No. 1, Januari $2016: 1$ - 12 
Pada Gambar 3 diatas merupakan tampilan penempatan komponen pada alat pengering rumput laut, dimana mikrokontroler diletakan dibagian atas kanan berdampingan dengan driver relay dan potensiometer kemudian ditutup dengan box hitam, dibagian atas box hitam juga terdapat tombol button untuk menyalakan alat dan mematikan alat, kemudian LCD 16x2 diletakan dibagian depan berdampingan dengan tombol putar untuk membesar kecilkan panas, kemudian element pemanas diletakan dibagian tengah dan di belakang element pemanas dipasang kipas untuk mendistribusikan panas, kemudian sensor DHT 11 diletakan di bagian kiri atas element pemanas.

Rancang bangun alat pengering rumput laut ini menggunakan mikrokontroler Arduino Uno, Mikrokontroler Arduino Uno bekerja dengan level tegangan 5 volt, Semua port digital pin 0 samapai dengan 13 dan pin analog 0 sampai 5 bersifat bi-directional I/O dengan internal pull-up. Untuk membangkitkan frekuensi kerja pada perancangan ini menggunakan osilator kristal sebesar $16 \mathrm{MHz}$, dengan inputnya berupa sensor suhu dan kelembaban DHT11, output rangkaian untuk menggerakkan dimmer element pemanas dan output berupa driver relay 5 volt untuk menyalakan kipas, dan sebuah output LCD 16x2 karakter untuk menampilkan data pembacaan sensor suhu dan kelembaban DHT11. Nilai pembacaan sensor berkisar dari $0^{\circ} \mathrm{C}$ hingga $50^{\circ} \mathrm{C}$ dengan pembacaan kelembaban dari $20 \%$ hingga $90 \%$ dengan supply tegangan sebesar 5 volt.

Rangkaian elemen pemanas merupakan piranti yang mengubah energi listrik menjadi energi panas melalui proses Joule Heating. Prinsip kerja elemen panas adalah arus listrik yang mengalir pada elemen menjumpai resistansinya, sehingga menghasilkan panas pada elemen. Dalam pembuatan tugas akhir ini menggunakan element pemanas dengan kipas DC untuk mendistribusikan panas kearea sekitar agar pemberian suhu panas dapat merata dengan baik. Pengendalian panas dari element menggunakan rangkaian dimmer $\mathrm{AC}$ yang dikontrol dengan potensiometer.

Secara garis besar alat pengering rumput laut ini terdiri dari dua bagian, yaitu perangkat keras (hardware) dan perangkat lunak (software). Perangkat lunak meggunakan program bahasa $\mathrm{C}$, untuk mempermudah dalam perancangan sistem kerja alat maka dapat dibuat terlebih dahulu flowchart sistem.

Secara garis besar alat pengering rumput laut ini terdiri dari dua bagian, yaitu perangkat keras (hardware) dan perangkat lunak (software). Perangkat lunak berupa program bahasa $\mathrm{C}$ untuk men-download program kedalam sistem mikrokontroler, untuk mempermudah dalam perancangan sistem kerja alat maka dapat dibuat terlebih dahulu flowchart sistem yang dapat dilihat pada Gambar 4.

Rancang Bangun Alat Pengering Rumput Laut..... (Anak Agung Gde Ekayana) 


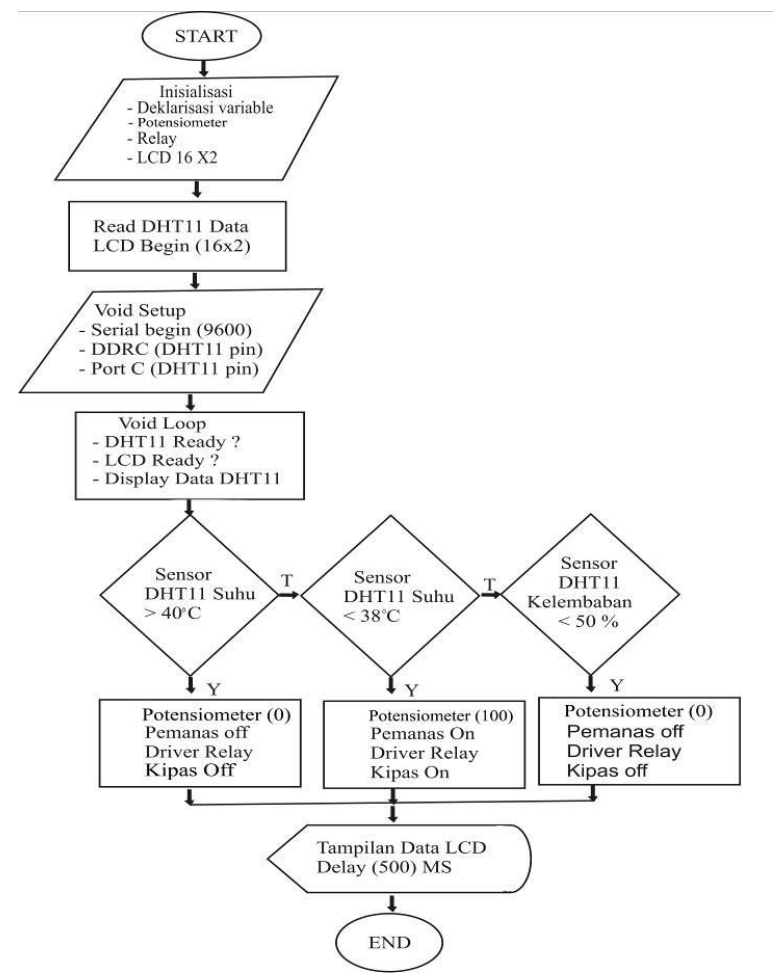

Gambar 4. Flowchart Program Alat Pengering Rumput Laut

\section{HASIL DAN PEMBAHASAN}

Pada tahap ini dilakukan pemasangan keseluruhan komponen, mulai dari pembuatan box pengering rumput laut sampai pemasangan komponen elektronika pada alat pengering rumput laut .

Pada tahap pertama pembuatan alat pengering rumput laut ini adalah pembuatan box dimana box ini berukuran 40x40x40 $\mathrm{cm}$ yang terbuat dari bahan triplek dengan tebal $7 \mathrm{~mm}$ seperti pada Gambar 5 berikut.

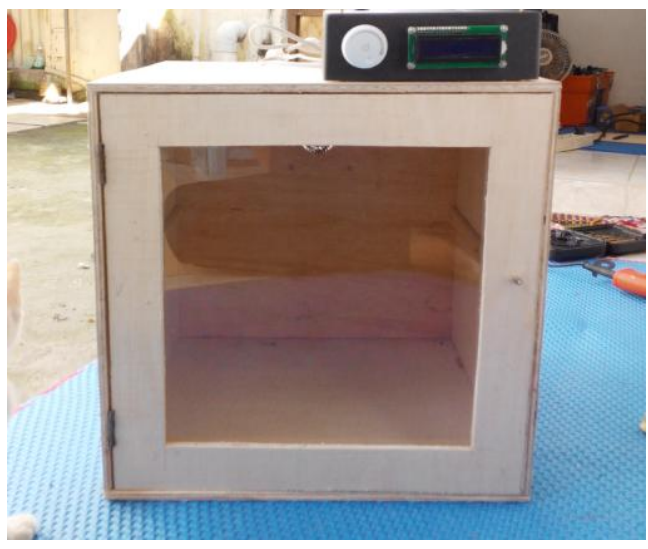

Gambar 5. Box Pengering Rumput Laut

JPTK, UNDIKSHA, Vol. 13, No. 1, Januari $2016: 1$ - 12 
Setelah pembuatan box selesai dilanjutkan dengan pembuatan komponen elektronik. Komponen yang dibuat adalah papan mikrokontroler seperti pada Gambar 6. Pertama buat desain terlebih dahulu lalu di print di atas plastik mika, selesai di print lalu di sablon menggunakan strika panas di atas papan PCB sampai menempel

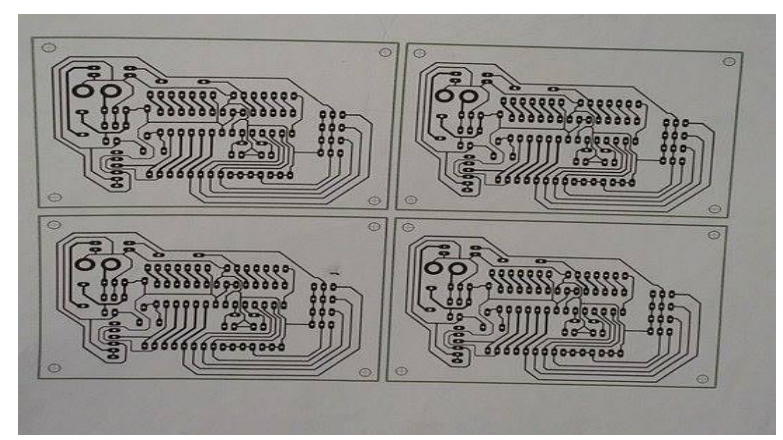

Gambar 6. Layout PCB

Pada tahap proses pensablonan sudah selesai, kemudian rendam dengan cairan ferri clorida secukupnya dan masukan air panas. Agar proses pelarutan lebih cepat wadah dapat digoyang-goyangkan agar tinta sablon larut dan menempel pada papan PCB. Setelah pelarutan dengan cairan ferri clorida selesai, maka dilanjutkan dengan pemotongan papan PCB sesuai dengan ukuranya. Tahap selanjutnya adalah pengeboran pada papan $\mathrm{PCB}$, pada proses pengeboran ini yang paling utama perlu diperhatikan adalah mata bor harus sesuai dengan ukuran dari kaki komponen yang akan dipasang pada lubang tersebut, pengeboran dilakukan pada tanda titik yang telah diberi tanda sebelumnya

Pembuatan papan PCB pada rangkaian driver relay memiliki proses yang sama dengan pembuatan rangkaian papan PCB untuk mikrokontroler. Setelah papan selesai dibuat lalu langkah selanjutnya adalah memasang komponen elektronika pada papan mikrokontroler dan juga Driver relay. Berikut gambar setelah rangkaian mikrokontroler dan rangkaian Driver relay selesai seperti pada Gambar 7.

Rancang Bangun Alat Pengering Rumput Laut...... (Anak Agung Gde Ekayana) 


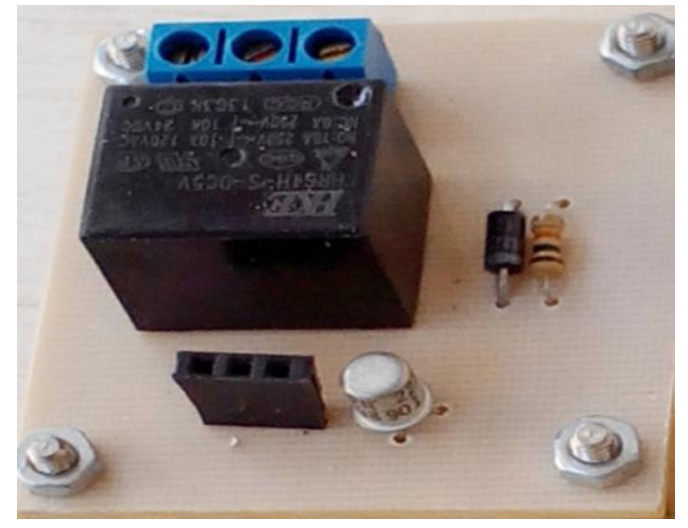

Gambar 7. Rangkaian Driver Relay Pada Papan PCB

Setelah komponen utama selesai di buat, selanjutnya melakukan pengecetan pada box rancang bangun alat pengering rumput laut agar penampilan lebih bagus dan lebih indah di lihat. Pada tahap proses pengecatan box sudah selesai kemudian dilanjutkan dengan pemasangan komponen. Komponen yang dipasang pertama adalah push button dimana komponen ini dipasang pada box hitam bagian atas, komponen ini digunakan untuk menyalakan alat pengering rumput laut dan mematikan alat pengering rumput laut . Tahap pemasangan komponen selanjutnya adalah mikrokontroler dan komponen lainnya dipasang didalam box hitam.

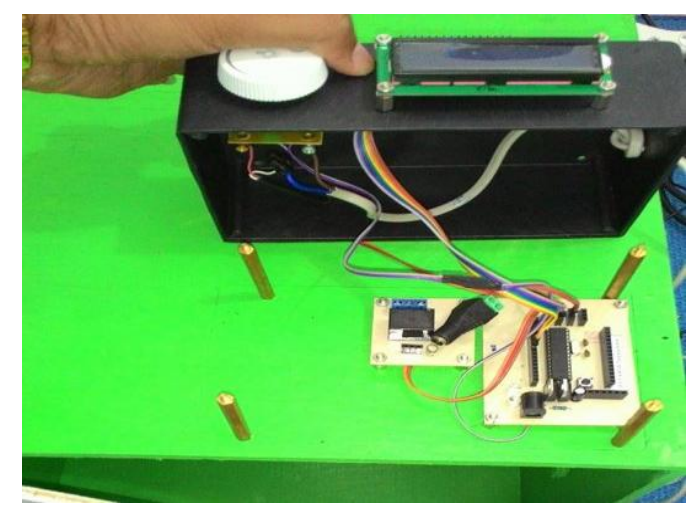

Gambar 8. Pemasangan Mikrokontroler ATMega328 dan Komponen Elektronika

Pengujian secara keseluruhan dilakukan untuk menguji seluruh komponen yang terdapat pada alat pengering rumput laut. Skenario pengujian pertama yaitu memasukan rumput laut ke dalam alat pengering rumput laut. Skenario pengujian kedua yaitu dengan melihat setiap beberapa jam nilai suhu dan kelmbabanya. Skenario pengujian yang ketiga dengan cara memperbandingkan hasil kekeringan rumput laut yang sudah kering dengan menggunakan sinar matahari kemudian dibandingkan dengan hasil kekeringan menggunakan pengeringan rumput laut . Skenario pengujian pertama adalah dengan cara

JPTK, UNDIKSHA, Vol. 13, No. 1, Januari $2016: 1$ - 12 
memasukan rumput laut basah kedalam alat pengering rumput laut, seperti pada Gambar 9.

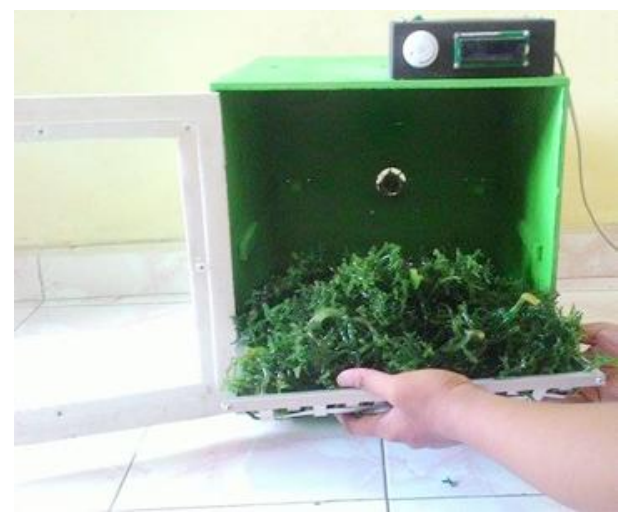

Gambar 9. Memasukan Rumput Laut Basah Kedalam Alat Pengering Rumput Laut.

Skenario pengujian kedua adalah dengan cara melihat setiap beberapa jam nilai suhu dan kelembabanya, seperti pada Gambar 10.

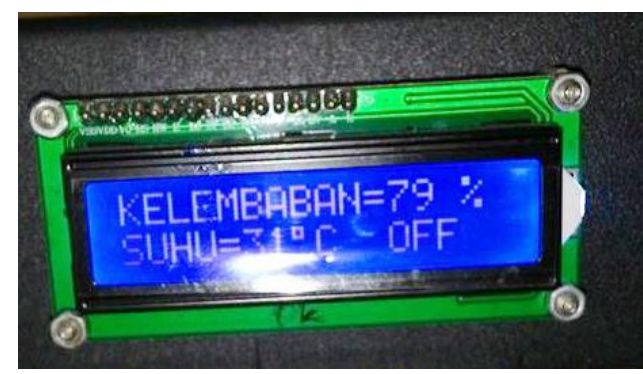

Gambar 10. Tampilan Suhu Dan Kelembaban Saat Rumput Laut Basah

Berikut adalah hasil tabel pengujian setiap perubahan nilai suhu dan kelembaban dari rumput laut basah yang di masukan ke dalam alat pengering rumput laut sampai dengan rumput laut kering, dengan membutuhkan waktu kurang lebih 7 jam.

Tabel 1. Pengujian Hasil Kekeringan Rumput Laut

\begin{tabular}{|c|c|c|c|l|}
\hline No & Suhu & Kelembaban & waktu & \multicolumn{1}{|c|}{ Keterangan } \\
\hline 1. & $31^{\circ} \mathrm{C}$ & $79 \%$ & - & Basah \\
\hline 2. & $37^{\circ} \mathrm{C}$ & $53 \%$ & 1 jam & Lumayan basah \\
\hline 3. & $38^{\circ} \mathrm{C}$ & $52 \%$ & 2 jam & Lumayan basah \\
\hline 4. & $38^{\circ} \mathrm{C}$ & $48 \%$ & 3 jam & Mulai kering \\
\hline 5. & $41^{\circ} \mathrm{C}$ & $42 \%$ & 4 jam & Lumayan kering \\
\hline 6. & $43^{\circ} \mathrm{C}$ & $38 \%$ & 5 jam & Lumayan kering \\
\hline 7. & $47^{\circ} \mathrm{C}$ & $36 \%$ & 6 jam & Hampir kering \\
\hline 8. & $49^{\circ} \mathrm{C}$ & $28 \%$ & 7 jam & Kering \\
\hline
\end{tabular}

Rancang Bangun Alat Pengering Rumput Laut...... (Anak Agung Gde Ekayana) 
Skenario pengujian ketiga dengan cara membandingkan hasil kekeringan rumput laut dengan pengeringan sinar matahari dengan pengeringan hasil pengeringan rumput laut, seperti pada Gambar 11 dan 12.

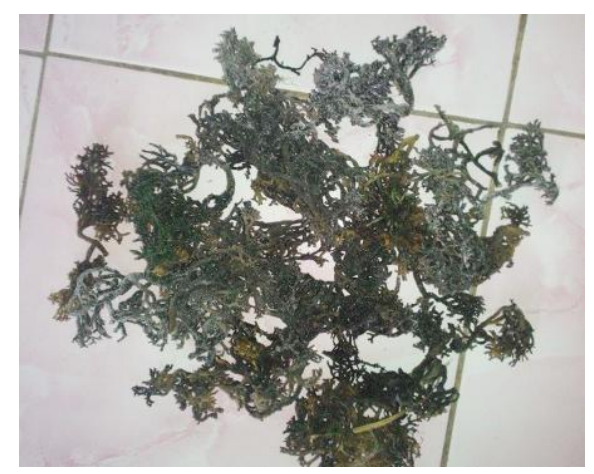

Gambar 11. Hasil Pengeringan Dengan Sinar Matahari

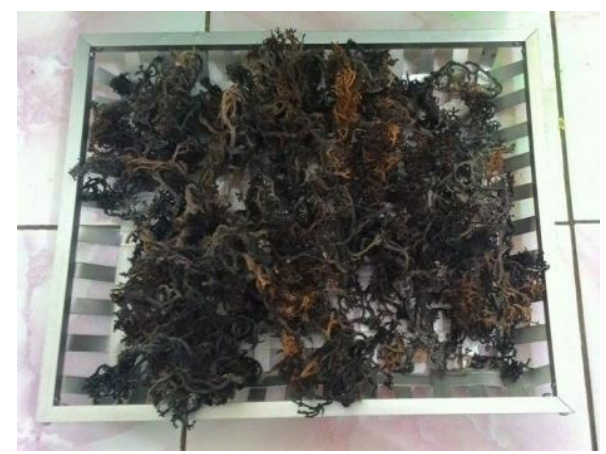

Gambar 12. Hasil Pengeringan Dengan Pengering Rumput Laut

Berdasarkan hasil pengujian keseluruhan, didapatkan hasil sebagai berikut dimana menurut pendapat petani rumput laut dan hasil pengamatan hasil pengeringan rumput laut dan membandingkan hasil dari kekeringan rumput laut dengan sinar matahari dengan alat pengering rumput laut, menyatakan bahwa alat pengering rumput laut ini mampu mengeringkan rumput laut sama dengan mengeringkan dengan sinar matahari bahkan alat pengering rumput laut ini mampu membuat kualitas rumput laut kering bersih dibandingkan dengan pengeringan rumput laut dengan sinar matahari.

\section{PENUTUP}

Berdasarkan hasil perancangan sistem dan pembuatan alat pengering rumput laut, dengan element pemanas (heater), sensor DHT11, LCD 16x2 dan mikrokontroler ATMega328 serta berpedoman pada literature yang berhubungan dengan sistem tersebut,

JPTK, UNDIKSHA, Vol. 13, No. 1, Januari $2016: 1$ - 12 
dengan melakukan percobaan yang bersifat ilmiah dapat mencapai hasil yang lebih optimal, maka dapat diambil kesimpulan dan saran-saran sebagai berikut.

Berdasarkan hasil penelitian terhadap masalah yang dibahas dalam tugas akhir ini, dapat ditarik beberapa kesimpulan seperti:

Secara keseluruhan sistem sudah bekerja dengan baik, dan mampu mengeringkan rumput laut. Tahapan pengujian unjuk kerja dari alat pengering rumput lautm yaitu:

a) Pertama memasukan rumput laut kedalam alat pengering.

b) Kedua dengan cara melihat setiap beberapa jam kenaikan nilai suhu dan kelembaban-nya.

c) Ketiga dengan cara membandingkan hasil kekeringan rumput laut dengan pengeringan sinar matahari, dengan pengeringan hasil pengeringan rumput laut .

Hasil pengujian keseluruhan menunjukkan bahwa alat pengering rumput laut ini mampu mengeringkan rumput laut selama 7 jam. Hasil pengujian sensor DHT11 mampu merespon perubahan nilai suhu dan kelembaban. Dapat diketahui bahwa jika suhu udara meningkat, maka kelembaban udara akan menurun

Dari pembuatan alat pengering rumput laut ini, dapat ditarik saran untuk pengembangan alat pengering rumput laut ini seperti.

1. Membuat ukuran penampung alat pengering rumput laut yang lebih besar supaya proses pengeringan rumput laut bisa menjadi lebih banyak.

2. Ditambahkan sistem menghemat energi, agar tidak terlalu banyak energi listrik yang digunakan, sehingga konsumsi listrik lebih efisien.

3. Bahan dasar box dari alat pengering rumput laut bisa menggunakan bahan yang lebih dapat memancarkan panas, sehingga pengeringan dapat lebih cepat dilakukan.

\section{DAFTAR PUSTAKA}

Agung Trawanda, Ariyati Restina, Sri. 2014. Kuantitas Dan Kualitas Rumput Laut Grcilaria sp. Bibit Hail Seleksi Dan Kultur Jaringan Dengan Budidaya Metode Longline. Journal Of Aquaaculture Management And Tecnology. Volume 3, No. 2.

Baihaq, Muquddas. 2009. Sistem Pengendali Peringatan Dini Kebakaran Pada Ruko (Ruman Toko) Melalui SMS (Short Message Service). Jurnal Neutrino. Volume 1, No. 2.

Budihartono, Widodo. 2010. Robotika Teori Dan Implementasi. Yogyakarta : Andi.

Rancang Bangun Alat Pengering Rumput Laut...... (Anak Agung Gde Ekayana) 
Ditjenkanbud. 2005. Profil Rumput Laut Indonesia DKP RI. Ditjenkanbud. Jakarta.

Estiasih, Teti dan Ahmadi,2009. Teknologi Pengolahan Pangan. Bumi Aksara. Malang.

Ginting, Natalia. 2012. Penggerakan Antena Modem USB Tiga Dimensi Berbahasa Mikrokomputer Menggunakan Arduini Uno. http://repoeitory .usu.ac.id /handle/ $123456789 / 35001$.

Hakim Rahmat. 2006. Studen Guide Series Mudah Merakit Komputer. Jakarta : PT. Elex Media Komputindo.

Iskandar. 2012. Sistem Informasi Geografis Untuk Pemetaan Daerah Rawan Gempa Tektonik Dan Jalur Evakuasi Di Yogyakarta. Volume 14, No. 1.

Novizan. 2000.. Petunjuk Penumpukan Yang Efektif. Agro Media Pustaka : Jakarta.

Risma Pola. 2013. Aplikasi Sensor NTC 47D-15 Dan Sensor Kelembaban 808H5V5 Pada Mesin Pengeing Daun Sungkai. Jurnal Elektron. Volume 5, No. 1.

Winoto. 2010. Mikrokontroler AVRATMega/16/31/8535 Dan Pemrograman Dengan Bahasa C Pada WinAVR. Bandung : Informatika.

JPTK, UNDIKSHA, Vol. 13, No. 1, Januari $2016: 1$ - 12 